\title{
Task Characteristics and Work Engagement: Exploring Effects of Role Ambiguity and ICT Presenteeism
}

\author{
Sang-Hoon Lee ${ }^{1}$, Yuhyung Shin ${ }^{2}$ and Seung Ik Baek ${ }^{2, *}$ \\ 1 School of Labor and Employment Relations, University of Illinois at Urbana-Champaign, Champaign, \\ IL 61820, USA; shl8@illinois.edu \\ 2 School of Business, Hanyang University, Seoul 04763, Korea; yuhyung@hanyang.ac.kr \\ * Correspondence: sbaek@hanyang.ac.kr; Tel.: +82-02-2220-1062
}

Received: 15 September 2017; Accepted: 6 October 2017; Published: 16 October 2017

\begin{abstract}
In order to secure organizational sustainability in a rapidly changing environment, it is necessary to implement a decentralized and flexible work environment. In such work environments, normally individuals are provided with autonomy and independence in performing tasks, thus allowing them to further engage in their given work. This study investigated task antecedents of work engagement, and further explored the process of how task characteristics affect work engagement. It focused on examining the mediating effect of role ambiguity on the task characteristics-work engagement relationship and the moderating effect of information and communication technology (ICT) presenteeism on the task characteristics-role ambiguity relationship through multiple regression analyses and a bootstrapping procedure on survey data collected from 202 South Korean employees. It found that task interdependence and autonomy were negatively associated with role ambiguity. Of the two task characteristics, only task interdependence had a negative relationship with role ambiguity, and this relationship was significantly moderated by ICT presenteeism such that the negative association between task interdependence and role ambiguity was more pronounced when ICT presenteeism was high than when it was low.
\end{abstract}

Keywords: work engagement; task interdependence; task autonomy; role ambiguity; ICT presenteeism

\section{Introduction}

As the business environment changes rapidly and competition in the market becomes more intense, the labor-intensive work sector is diminishing and the knowledge-intensive work sector is increasing. While labor-intensive work requires employees to passively perform given tasks, knowledge-intensive work ask employees to decide the scope and the method of tasks actively by considering their own capabilities and surroundings. For labor-intensive work, factors such as appropriate reward systems and clear job definitions might have a major impact in promoting work engagement. Work engagement in a rapidly changing business environment is critical to securing organizational sustainability [1]. However, these factors do not provide sufficient motivation for employees to engage in knowledge-intensive work. Normally, knowledge-intensive work does not include predefined task definitions and scope, but rather it is necessary to constantly make changes according to the situation. For this reason, the close cooperation of fellow employees and ensuring job autonomy plays a very important role in generating work engagement. Work engagement is defined as "a positive, fulfilling, work-related state of mind that is characterized by vigor, dedication, and absorption" [2]. Scholars and companies have been working hard for many years to identify the factors that can induce work engagement. This study investigates the task antecedents of work engagement.

This study examines two types of task characteristics-task interdependence and task autonomy - which presumably motivate employees to be engaged in their work. Task interdependence 
is defined as the degree to which an individual's designed tasks and job require coordination with other team members regarding activities, information, physical materials, support, and expertise [3-5]. Task autonomy refers to the degree to which the job provides substantial freedom, independence, and discretion for the employee in scheduling work and in determining the procedures to be used in carrying it out [6]. Despite the importance of these two task characteristics in predicting work engagement, the mediating and moderating processes affecting this relationship are still unclear in the literature. To fill this gap, we identify role ambiguity as an intermediary process linking task interdependence and autonomy to work engagement.

We also explore that the relationship between two task characteristics and work engagement is further moderated by information and communication technologies (ICT). With the development of ICT, we are using it as a major tool for almost all the tasks we perform today. This ICT-based work environment has changed the ways we perform tasks as well as the tasks themselves. In the ICT-based work environment, it is more convenient to perform tasks while maintaining close relationships with colleagues rather than doing them alone. Furthermore, because information needed in performing tasks can be easily searched using ICT, more job autonomy can be attained with ICT. Ayyagari and colleagues (2011) [7] define ICT presenteeism as "the degree to which technology enables users to be reachable." The effect of ICT presenteeism may induce employee stress [7-9], but may also be a factor that facilitates interaction and communication among individuals [7]. Thus, we expect ICT presenteeism to play a facilitative role by strengthening the effect of task interdependence and autonomy on role ambiguity. This study examines the mediating effect of role ambiguity and the moderating effect of ICT presenteeism on the relationship between two task characteristics (task interdependence and autonomy) and work engagement.

\section{Theoretical Framework and Hypothesis Development}

\subsection{Exploring the Relationship between Task Characteristics and Work Engagement}

We propose two task characteristics, task interdependence and task autonomy, which are commonly observed and experienced in the workplace. As work becomes complicated, employees cannot perform their work alone and therefore, they should work in close cooperation with their colleagues. Through the delegation of authority, the autonomy of work has been used as a major motivator for employees. The study links task interdependence and task autonomy to work engagement, as the two task characteristics that individuals experience positively affects how much time and effort they devote to their work as a whole (i.e., vigor), how they experience their tasks as meaningful (i.e., dedication), and the extent to which they are engrossed in and fully concentrating on their roles (i.e., absorption) [10]. Self-determination theory (SDT) [11,12] can explain the positive link between two task characteristics and work engagement. The basic tenet of SDT is that needs represent "innate psychological nutriments" that are essential elements for continuous growth, integrity, social development, and personal well-being [12]. Deci and Ryan (1985) [13] identified three types of needs that foster optimal personal well-being: the need for competence, autonomy, and relatedness. The need for competence is considered as an element that energizes human activity among individuals who exhibit a major propensity to have an impact on the environment and achieve valued outcomes for themselves [11]. The need for autonomy is the desire to experience freedom in organizing and deciding one's experiences and integrity so that one may perceive a sense of self [11]. The need for relatedness is the desire to feel connected to others such as other employees and supervisors within organizations. When task or job conditions that meet these needs are provided by and/or are present in a team or organization, employees are more likely to engage in their jobs [14].

Task interdependence is expected to enhance work engagement through the fulfillment of the need for relatedness. Employees who engage in interpersonal interactions are more likely to be intrinsically motivated when they experience relational attachments [11]. Individuals who work interdependently can easily fulfill their need for relatedness because they are allowed to express work-related issues 
to each other, assisting employees in embarking on close and intimate relationships with colleagues and supervisors [15]. Moreover, task interdependence is likely to be linked to relational energy, a source of energy for individuals provided by social interaction in groups that enhance task and role capacity $[8,16]$. In interdependent work environments where social interactions are essential and represent the key to success, the fulfillment of the needs of employees performing interdependent tasks results in positive outcomes such as work engagement.

On the other hand, task autonomy is beneficial to work engagement by satisfying the needs for competence and autonomy. In job demands-resources (JD-R) theory [17], task autonomy is an important job resource that motivates employees' functioning. Job resources stimulate employees' motivational processes, fulfilling basic psychological needs such as autonomy and competence, achieving work goals, and reducing stressful and energetic job demands [18]. This is important because task autonomy can fulfill the need for both autonomy and competence simultaneously. The need to control one's behavioral outcomes and to take an action based on a sense of volition [11] is satisfied by making personal choices. When employees are empowered to make decisions about their tasks, goals, workload, work schedules, and feedback, they are likely to feel competent. Thus, task autonomy serves as one condition for satisfying the need for competence. Task autonomy also helps employees fulfill their need for autonomy because it enables them to act upon their discretion and master their environment, thus producing a feeling of autonomy [15]. Importantly, the JD-R literature has found that resources are the most important predictor of work engagement $[19,20]$. A meta-analysis study carried out by Halbesleben (2010) [21] found that specific resources such as autonomy/job control and self-efficacy were positively correlated with work engagement. Similarly, a longitudinal study designed by Schaufeli and colleagues (2009) [22] found that an increase in autonomy and social support significantly predicted work engagement. Drawing on these findings, we formulate the following hypothesis:

Hypothesis 1. (a) Task interdependence and (b) task autonomy are positively related to work engagement.

\subsection{Exploring the Relationship between Task Characteristics and Role Ambiguity}

Employees experience role ambiguity when they are uncertain about what their team or organization expects from them and thus lack certainty and clarity about what they should accomplish [23]. Although the literature lacks research on the direct link between task characteristics and role ambiguity, we predict that task interdependence and autonomy attenuate role ambiguity. Effective and efficient outcomes stemming from task interdependence may be postulated on the premise that social support is present during interactions with other team members or significant others (i.e., supervisors), since employees rely on others for information about role expectations [24]. This is consistent with the view that the presence of social support has a strong buffering effect on workplace stressors [25]. Likewise, supervisor support or support from team members when engaging in interdependent tasks reduces role ambiguity and enhances role clarity, thus positively affecting individual productivity levels, job satisfaction and organizational commitment [26]. When employees work interdependently, they share more information, knowledge, and feedback and have more opportunities to clarify each other's roles. As a result, task interdependence should be associated with decreased role ambiguity.

On the other hand, a decrease in role ambiguity can also be achieved through autonomous tasks. Miao and Evans' (2013) [27] study on salesperson performance showed that capability control is a critical job resource that amplifies the negative effect of managerial control on role ambiguity, which suggests that task autonomy plays a paramount role in reducing job ambiguity. Autonomous tasks allow employees a high degree of control and discretion over their work. Employees can determine the content, scope, and boundary of their tasks, thereby experiencing less role ambiguity. This line of reasoning leads to the following hypothesis: 
Hypothesis 2. (a) Task interdependence and (b) task autonomy are negatively related to role ambiguity.

\subsection{Exploring the Mediating Effect of Role Ambiguity}

Gilboa and colleagues (2008) [28] claimed that role stressors have two basic dimensions: hindrance and challenge. Role ambiguity is high in hindrance and low in challenge, impeding employees' work achievements and development [28]. In line with this reasoning, JD-R theory identifies role ambiguity as an example of a hindrance job demand. According to JD-R theory, hindrance job demands thwart personal growth and goal attainment [29] and elicit negative emotions, which prevent employees from being engaged in their work [30]. Meta-analytic findings have consistently verified that role ambiguity has the strongest negative influence on individuals' performance [28]. Furthermore, role ambiguity negatively affects self-efficacy, whereby individuals may not believe in their ability to perform given tasks due to the ambiguity on their roles [31,32]. This may stem from employees' view that, if their role is unclear, performance levels are uncontrollable and less visible, thereby reducing their confidence in and commitment to a specific task, which are required to ensure optimal performance [31,32]. We therefore predict a negative association between role ambiguity and work engagement and propose the following:

Hypothesis 3. Role ambiguity is negatively related to work engagement.

Integrating the aforementioned relationships, role ambiguity is posited to mediate the relationship between task interdependence and autonomy and work engagement. When employees work on interdependent tasks, they are likely to experience less role ambiguity due to increased information sharing. Likewise, autonomous tasks reduce role ambiguity by enhancing employees' control over their work content and processes. The decreased level of role ambiguity should be positively associated with work engagement. Following this logic, we formulate the following hypotheses:

Hypothesis 4a. Role ambiguity mediates the relationship between task interdependence and work engagement.

Hypothesis $\mathbf{4 b}$. Role ambiguity mediates the relationship between task autonomy and work engagement.

\subsection{Exploring the Moderating Effect of ICT Presenteeism}

Drawing on MRT (Media Richness Theory) [33], we postulate that ICT presenteeism serves as a boundary condition influencing the relationship between task interdependence/autonomy and role ambiguity. The degree to which individuals perceive their relatedness and reachability to others due to ICT mediums should amplify the negative effect of job characteristics on role ambiguity. The basic premise of this theory is that communication mediums determine the effectiveness of solutions to information and communication issues related to uncertain and/or equivocal tasks, roles, objectives, and goals in the workplace [33]. Thus, when ICT is prevalent in the workplace, it contributes not only to information gathering but also to the reduction of uncertainty, thereby enhancing the efficiency and effectiveness of employees' work processes and outcomes [33]. ICT presenteeism represents a boundary condition in which media richness is high since ICT enables an increase in the communication flow between stakeholders within a team or organization. This occurs because, for an individual to be effectively reachable anytime and anywhere, ICT mediums must be developed, allowing immediate feedback through various channels that embrace visual and audio functions [34]. Employee's perceptions of ICT presenteeism amplify the power of task characteristics to reduce ambiguity on roles and tasks by facilitating information processing and communication. The degree to which ICT enables its users to be reachable to each other stimulates information flow, which reduces equivocality and helps lead to agreements on the roles and tasks individuals experience in their immediate teams or in distal organizations. 
According to MRT, ICT helps reduce lack of clarity at work, which strengthens the connection between task interdependence and role ambiguity. Regardless of whether the situation at hand is uncertain or not, ambiguous and unclear events can provoke managers and employees to seek common ground and gather opinions among task-dependent workers [33]. Workers exchange views via communication mediums to clarify issues and share a common perspective, which, during interaction with others regarding tasks, may enact cooperative behavior [34]. Under these circumstances, although interaction among employees while they perform tasks will usually decrease ambiguity in the workplace, ICT is an effective communication tool with which to prompt this mechanism because being connected to others regardless of space and time assists employees in identifying the problems they face, thus implying that equivocality reduction is closely related to pinpointing fundamental task issues. Therefore, ICT presenteeism is likely to strengthen the impact of task interdependence on role ambiguity. Task interdependence should thus be associated with less role ambiguity when ICT presenteeism is high than when it is low.

Building on MRT, ICT presenteeism should also strengthen the influence of task autonomy on role ambiguity. Fujimoto and colleagues (2016) [35] researched mobile technology usage, finding that ICT technology enhanced work engagement through job autonomy. This indicates the substantial positive effect of ICT usage in the workplace. In other words, ICT acts as a job resource for its users, as it can inhibit technostress by facilitating involvement and engagement with a new technology, further advancing usage and participation [36]. With the help of ICT, employees can better determine or modify their work content and processes, which in turn leads to decreased role ambiguity. Thus, the link between task autonomy and role ambiguity should be stronger when ICT presenteeism is high than when it is low. Indeed, Daft and colleagues (1987) [34] found that effective workplace performers were more sensitive to the richness of the medium and preferred rich ICT communication tools to deal with any potential communication. Thus, a similar level of task autonomy should lead to decreased role ambiguity when individuals employ the rich ICT mediums available in their organization. We thus propose the following:

Hypothesis 5a. The relationship between task interdependence and role ambiguity is moderated by ICT presenteeism, such that the negative relationship is stronger when ICT presenteeism is high than when it is low.

Hypothesis $\mathbf{5 b}$. The relationship between task autonomy and role ambiguity is moderated by ICT presenteeism, such that the negative relationship is stronger when ICT presenteeism is high than when it is low.

\section{Research Methodology}

\subsection{Sample and Data Collection Procedure}

Data was collected via a constructed survey questionnaire at a single point in time. We selected sample organizations based on the voluntary participation of part-time MBA students of three major Korean universities. By considering the type and the size of the businesses, we selected 25 organizations for our study. We asked the students who had expressed willingness to participate to voluntarily distribute questionnaires to their colleagues. A total of 250 surveys were distributed to the employees in the sponsoring organizations, resulting in the collection of 215 samples (response rate $=86.0 \%$ ). However, after removing incomplete questionnaires, our final sample consisted of 202 participants (response rate $=80.8 \%$ ). The average age and organizational tenure of the respondents were 33.2 years $(\mathrm{SD}=8.4)$ and 4.4 years $(\mathrm{SD}=5.9)$, respectively. Forty percent of the respondents were female and $19.9 \%$ of the sample held managerial positions. The respondents belonged to diverse industries and worked in the public/government-based $(56.4 \%)$, service sector $(20.0 \%)$, retail $(10.2 \%)$, manufacturing $(9.8 \%)$, and financial business (3.7\%) firms. Since the study focused on exploring factors that affected their work engagement from an individual employee's perspectives, it did not consider the impact of the organizational structure and culture. In order to minimize the influence of these factors, this study tried to balance the public and the private sectors in the sample size. 


\subsection{Measures}

Survey items were constructed following Brislin's (1986) [37] back-translation procedure. All items were measured on a 5-point Likert scale, ranging from 1 ("never") to 5 ("always").

Task interdependence. To assess task interdependence, we used seven items $(\alpha=0.88)$ from Campion et al.'s (1993) [36] task characteristics scale. Sample items include, "I cannot accomplish my tasks without information or materials from other members of my team," "Within my team, jobs performed by team members are related to one another," and "Other members of my team depend on me for information or materials needed to perform their tasks."

Task autonomy. Task autonomy was assessed with four items $(\alpha=0.89)$ from Hackman and Oldham's (1980) [38] Job Diagnostic Survey, such as "My job permits me to decide independently how to go about doing the work," and "My job gives me considerable opportunity for independence and freedom with respect to how I do the work."

Role ambiguity (reverse coding). Role ambiguity was measured with six items $(\alpha=0.84)$ from Rizzo et al. (1970) [23], with all items reverse-coded prior to analyses. Examples include, "In my job, I know exactly what is expected of me," "I know that I have divided my time properly in my job," and "My roles and responsibilities are clear to me."

ICT presenteeism. We evaluated ICT presenteeism with four items $(\alpha=0.94)$ from Ayyagari and colleagues' (2011) [7] scale, such as "The use of ICTs enables others to have access to me" and "The use of ICTs enables me to be in touch with others."

Work engagement. We measured work engagement using Schaufeli et al.'s (2006) [39] nine-item Utrecht Work Engagement Scale (UWES) ( $\alpha=0.91$ ), with factors, such as "At my work, I feel energetic" "I am enthusiastic about my job," and "I feel happy when I am working intensely."

Control variables. We used eight control variables: age, gender dummy variable, job-level dummy variables, four industry dummy variables (i.e., manufacturing, financial business, retail, and service), organizational tenure, and positive affect. Of these, positive affect was included following Podsakoff et al.'s (2003) [40] recommendation for dealing with common method variance (CMV). Podsakoff et al. (2003) [40] claimed, that because positive affect is a common source of CMV, positive affect should be controlled as a common method factor. Scholars have also pointed out that positive affect should be controlled due to its influence on positive work aspects such as work engagement [41].

\subsection{Statistical Analysis Strategies}

To test our hypotheses, we performed multiple hierarchical regression analyses. As a preliminary step, we conducted confirmatory factor analysis (CFA) with AMOS 22.0 to assess the discriminant validity of the variables. Then, we carried out hierarchical regression analyses for the proposed main effects and moderation effects, and applied Baron and Kenny's (1986) [42] method of testing a mediation effect. To reduce multicollinearity, we mean-centered the independent variables (i.e., task interdependence and task autonomy) and the moderator variable (i.e., ICT presenteeism) in moderation analyses. To probe the pattern of the proposed moderation effects, we created interaction graphs by calculating the interaction slopes of the regression equation, plotting $1 \mathrm{SD}$ above and $1 \mathrm{SD}$ below the mean level of ICT presenteeism, respectively.

\section{Results}

Our CFA results are displayed in Table 1. We performed CFA on items measuring task interdependence, task autonomy, ICT presenteeism, role ambiguity, and work engagement. The results demonstrate that the hypothesized five-factor model $\left(\chi^{2}=763.72, \mathrm{CFI}=0.90, \mathrm{TLI}=0.88, \mathrm{RMSEA}=0.07\right)$ fitted our data significantly better than the alternative models, which gradually showed sub-standard absolute fit levels: $\chi^{2}=1269.33, \mathrm{CFI}=0.77, \mathrm{TLI}=0.73, \mathrm{RMSEA}=0.11$ for the four-factor model combining task interdependence and task autonomy; $\chi^{2}=1546.38, \mathrm{CFI}=0.70, \mathrm{TLI}=0.65, \mathrm{RMSEA}=0.12$ for the three-factor model combining task interdependence, task autonomy, and role ambiguity; 
$\chi^{2}=1990.54, \mathrm{CFI}=0.59, \mathrm{TLI}=0.51, \mathrm{RMSEA}=0.14$ for the three-factor model combining task interdependence, task autonomy, and ICT presenteeism; $\chi^{2}=2242.88$, CFI $=0.52$, TLI $=0.44$, RMSEA $=0.15$ for the two-factor model combining task interdependence, task autonomy, role ambiguity, and ICT presenteeism. These factor-analytic results suggest that CMV was not a serious threat to our data [40], thus confirming the discriminant validity of our measures.

Table 1. Results of Confirmatory Factor Analyses and Chi-Square Difference Test.

\begin{tabular}{|c|c|c|c|c|c|c|c|}
\hline Model & $x^{2}$ & df & $\Delta \chi^{2}(\Delta d f)$ & $p$-Value & CFI & TLI & RMSEA \\
\hline - Hypothesized five-factor model & 763.05 & 364 & - & - & 0.90 & 0.88 & 0.07 \\
\hline $\begin{array}{l}\text { - Four-factor model (combining task } \\
\text { interdependence and task autonomy into a } \\
\text { single factor) }\end{array}$ & 1269.33 & 368 & $506.28(4)$ & $<0.001$ & 0.77 & 0.73 & 0.11 \\
\hline $\begin{array}{l}\text { - Three-factor model (combining task } \\
\text { interdependence, task autonomy, and role } \\
\text { ambiguity into a single factor) }\end{array}$ & 1546.38 & 371 & 783.33(7) & $<0.001$ & 0.70 & 0.65 & 0.12 \\
\hline $\begin{array}{l}\text { - Three-factor model (combining task } \\
\text { interdependence, task autonomy, and ICT } \\
\text { presenteeism into a single factor) }\end{array}$ & 1990.54 & 371 & $1227.49(7)$ & $<0.001$ & 0.59 & 0.51 & 0.14 \\
\hline $\begin{array}{l}\text { - Two-factor model (combining task } \\
\text { interdependence, task autonomy, role ambiguity, } \\
\text { and ICT presenteeism into a single factor) }\end{array}$ & 2242.88 & 373 & 1479.83(9) & $<0.001$ & 0.52 & 0.44 & 0.15 \\
\hline
\end{tabular}

CFI = comparative fit index; TLI = Tucker-Lewis index; RMSEA = root mean square error of approximation.

Table 2 presents the descriptive statistics and intercorrelations of the study variables. Hypotheses $1 \mathrm{a}$ and $1 \mathrm{~b}$ predicted a positive association between task interdependence/autonomy and work engagement, respectively. To test these hypotheses, we regressed work engagement on the control variables in the first step and task interdependence and autonomy in the second step. As depicted in Model 5 of Table 3, of the two task characteristics associated with work engagement, only task interdependence $(\beta=0.21, p<0.001)$ predicted work engagement, thus supporting Hypothesis 1a while rejecting Hypothesis $1 \mathrm{~b}$.

Hypotheses $4 \mathrm{a}$ and $4 \mathrm{~b}$ predicted the mediating effect of role ambiguity on the task characteristics-work engagement relationship. According to Baron and Kenny (1986) [42], when the mediator is added to the regression equation, the effect of the independent variable on the dependent variable should become insignificant (full mediation) or weaker (partial mediation). As shown in Model 6 of Table 3, the effect of task interdependence $(\beta=0.18, p<0.01)$ on work engagement became attenuated when role ambiguity $(\beta=-0.15, p<0.05)$ was included in the model, suggesting partial mediation. However, because we detected no significant relationship between task autonomy and work engagement, we could not proceed to test the mediating effect of role ambiguity for task autonomy. Therefore, Hypothesis $4 \mathrm{a}$ was supported, whereas Hypothesis $4 \mathrm{~b}$ was rejected.

Hypotheses $5 \mathrm{a}$ and $5 \mathrm{~b}$ proposed a moderating effect of ICT presenteeism on the relationship between task interdependence and autonomy and role ambiguity, respectively. The results of the hypotheses tests are presented in Model 3, Table 3. Of the two interaction terms, only the interaction between task interdependence and ICT presenteeism $(\beta=-0.14, p<0.05)$ was significant. In Figure 1 , we further plotted the interaction effect between task interdependence and ICT presenteeism on role ambiguity. As predicted, the negative relationship between task interdependence and role ambiguity was more pronounced when ICT presenteeism was high than when it was low. These findings lend support to Hypothesis 5 a. 
Table 2. Descriptive Statistics and Intercorrelations.

\begin{tabular}{|c|c|c|c|c|c|c|c|c|c|c|c|c|c|c|c|c|}
\hline Variable & $\mathbf{M}$ & SD & 1 & 2 & 3 & 4 & 5 & 6 & 7 & 8 & 9 & 10 & 11 & 12 & 13 & 14 \\
\hline Age & 33.16 & 8.40 & - & & & & & & & & & & & & & \\
\hline Gender dummy & 0.41 & 0.49 & $0.22 * *$ & - & & & & & & & & & & & & \\
\hline Job level dummy & 0.20 & 0.40 & $0.51 * *$ & $0.32 * *$ & - & & & & & & & & & & & \\
\hline Industry dummy 1 & 0.10 & 0.30 & -0.05 & $0.27 * *$ & 0.11 & - & & & & & & & & & & \\
\hline Industry dummy 2 & 0.04 & 0.19 & $-0.17^{*}$ & $0.19 * *$ & -0.10 & -0.06 & - & & & & & & & & & \\
\hline Industry dummy 3 & 0.10 & 0.30 & $-0.18^{* *}$ & 0.09 & -0.09 & -0.11 & -0.07 & - & & & & & & & & \\
\hline Industry dummy 4 & 0.20 & 0.40 & -0.01 & -0.06 & 0.10 & $-0.17^{*}$ & -0.10 & $-0.17^{*}$ & - & & & & & & & \\
\hline Organizational tenure & 4.35 & 5.92 & $0.61 * *$ & 0.14 * & $0.44 * *$ & 0.07 & -0.09 & $-0.19 * *$ & $0.14 *$ & - & & & & & & \\
\hline Positive affect & 3.29 & 0.88 & 0.12 & $0.22 * *$ & 0.03 & 0.04 & 0.06 & 0.04 & -0.18 ** & 0.10 & - & & & & & \\
\hline Task interdependence & 4.01 & 0.72 & -0.03 & 0.05 & -0.06 & -0.01 & 0.08 & 0.10 & 0.04 & 0.02 & $0.33^{* *}$ & $(0.88)$ & & & & \\
\hline Job autonomy & 3.17 & 0.93 & $0.34^{* *}$ & $0.14 *$ & $0.21 * *$ & -0.01 & 0.02 & -0.08 & -0.01 & $0.37 * *$ & $0.38^{* *}$ & $0.20 * *$ & $(0.89)$ & & & \\
\hline Role ambiguity & 2.22 & 0.65 & $-0.21 * *$ & -0.10 & -0.10 & -0.05 & -0.02 & 0.05 & 0.10 & $-0.19^{* *}$ & $-0.48^{* *}$ & $-0.32 * *$ & $-0.43^{* *}$ & $(0.84)$ & & \\
\hline IT presenteeism & 3.65 & 0.86 & -0.11 & 0.07 & 0.05 & 0.12 & 0.12 & -0.07 & -0.02 & 0.05 & $0.15^{*}$ & $0.20 * *$ & $0.20 * *$ & $-0.21 * *$ & $(0.94)$ & \\
\hline Work engagement & 3.39 & 0.75 & $0.28 * *$ & 0.12 & 0.14 & -0.01 & 0.03 & 0.07 & -0.05 & $0.20 * *$ & $0.64^{* *}$ & $0.41 * *$ & $0.38 * *$ & $-0.50 * *$ & $0.15 *$ & $(0.91)$ \\
\hline
\end{tabular}

$\mathrm{N}=202$; numbers in parentheses represent alphas; $\mathrm{M}=$ Mean; $\mathrm{SD}=$ Standard Deviation; ${ }^{*} p<0.05^{* *} p<0.01,{ }^{* * *} p<0.001$. 
Table 3. Results of Hierarchical Regression Analyses.

\begin{tabular}{|c|c|c|c|c|c|c|}
\hline \multirow{2}{*}{ Variable } & \multicolumn{3}{|c|}{ DV: Role Ambiguity } & \multicolumn{3}{|c|}{ DV: Work Engagement } \\
\hline & Model 1 & Model 2 & Model 3 & Model 4 & Model 5 & Model 6 \\
\hline Age & -0.17 & -0.16 & $-0.18 *$ & $0.27^{* *}$ & $0.26^{* *}$ & $0.24^{* *}$ \\
\hline Gender dummy & 0.07 & 0.06 & 0.05 & $-0.13 *$ & $-0.13 *$ & $-0.12 *$ \\
\hline Job level dummy & 0.03 & 0.03 & 0.05 & 0.01 & 0.02 & 0.02 \\
\hline Industry dummy 1 & -0.05 & -0.05 & -0.06 & 0.08 & 0.08 & 0.07 \\
\hline Industry dummy 2 & -0.04 & -0.01 & 0.01 & 0.10 & 0.07 & 0.07 \\
\hline Industry dummy 3 & 0.01 & 0.01 & 0.00 & $0.15^{*}$ & $0.12 *$ & $0.13 *$ \\
\hline Industry dummy 4 & 0.00 & 0.02 & 0.01 & 0.13 & 0.10 & 0.11 \\
\hline $\begin{array}{l}\text { Organizational } \\
\text { tenure }\end{array}$ & -0.05 & 0.02 & 0.03 & -0.01 & -0.03 & -0.03 \\
\hline Positive affect & $-0.46^{* * *}$ & $-0.31 * * *$ & $-0.35^{* * *}$ & $0.66^{* * *}$ & $0.57^{* * *}$ & $0.52 * * *$ \\
\hline $\begin{array}{l}\text { Task } \\
\text { interdependence }\end{array}$ & & $-0.15^{*}$ & $-0.16^{*}$ & & $0.21 * * *$ & $0.18^{* *}$ \\
\hline Task autonomy & & $-0.24 * *$ & $-0.23 * *$ & & 0.07 & 0.03 \\
\hline ICT presenteeism & & -0.11 & -0.09 & & & \\
\hline $\begin{array}{l}\text { Task } \\
\text { interdependence } x\end{array}$ & & & $-0.14^{*}$ & & & \\
\hline $\begin{array}{l}\text { ICT presenteeism } \\
\text { Task autonomy x }\end{array}$ & & & & & & \\
\hline $\begin{array}{l}\text { Task autonomy } \mathrm{x} \\
\text { ICT presenteeism }\end{array}$ & & & -0.00 & & & \\
\hline Role ambiguity & & & & & & $-0.15^{*}$ \\
\hline Total $R^{2}$ & 0.23 & 0.31 & 0.32 & 0.47 & 0.51 & 0.52 \\
\hline$\triangle R^{2}$ & - & 0.08 & 0.01 & - & 0.04 & 0.01 \\
\hline$\triangle \mathrm{F}$ & $7.41 * * *$ & $8.51 * * *$ & 2.57 & $20.29^{* * *}$ & $8.88 * * *$ & $6.18 *$ \\
\hline
\end{tabular}

$\mathrm{N}=202$; standardized regression coefficients are reported; DV = Dependent variables; ${ }^{*} p<0.05,{ }^{* *} p<0.01$, $* * * p<0.001$.

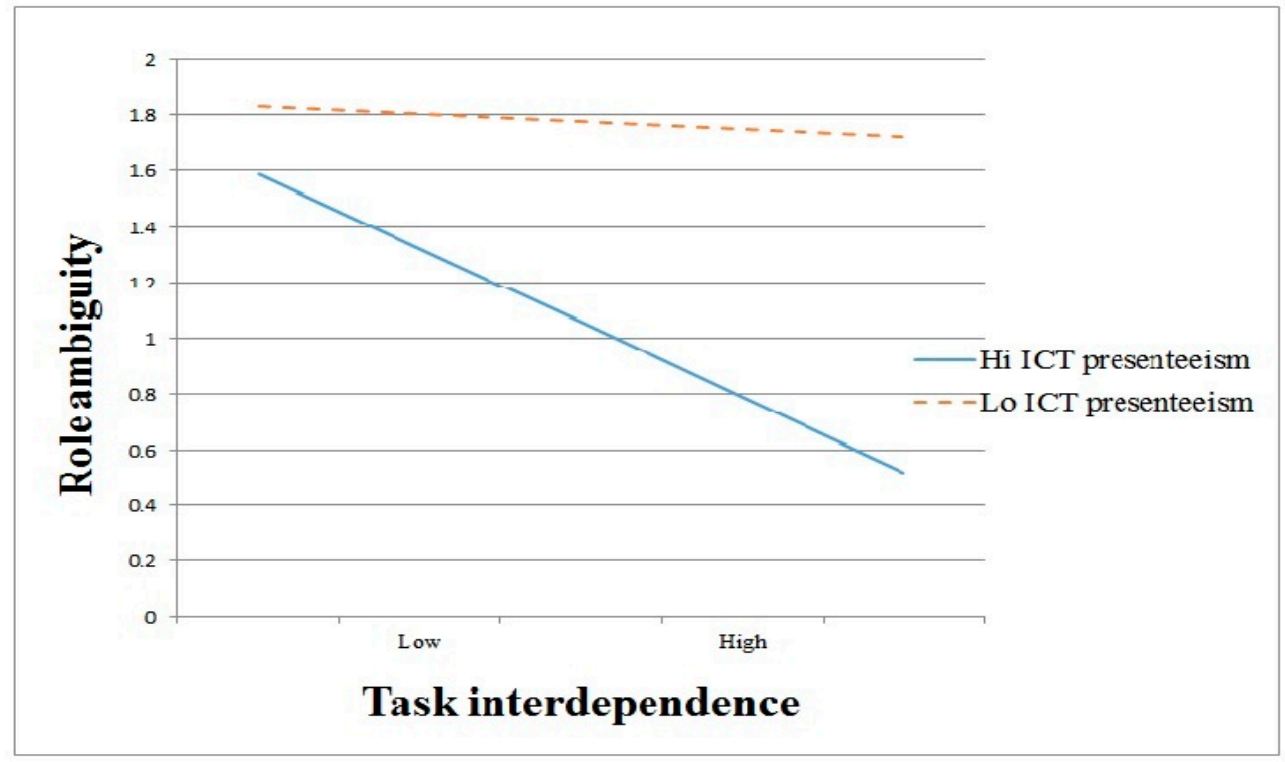

Figure 1. Interaction Effect Graph.

\section{Discussion}

Despite the increasing research on task characteristics and work engagement in organizational research, the mediating and moderating processes affecting their relationship remain unclear. We proposed role ambiguity as a mediator and ICT presenteeism as a moderator. Our findings showed that both task interdependence and task autonomy were negatively associated with role ambiguity. However, the moderating effect of ICT presenteeism was supported only for task interdependence. Likewise, the mediating effect of role ambiguity and the moderated mediating 
effect of ICT were validated only for task interdependence. As expected, the negative relationship between task interdependence and role ambiguity was more profound when ICT presenteeism was high. We describe our contributions to the work design, workplace stress, and work engagement literature in detail below.

As a widely used tool for performing business tasks, ICT has provided us with the competence to perform additional tasks beyond what employees were able to do in the past, improving work productivity to an unprecedented extent. However, for the same reason, some employees and managers have become concerned about the ambiguity of roles and tasks due to the increase in the information employees must process. We examined the moderating effect of ICT presenteeism in the process of individual task characteristics affecting work engagement. As a result, task interdependence was discovered to reduce role ambiguity, and this effect was amplified by ICT presenteeism. Given that interdependent tasks require coordination of activities, information, and physical support [3-5], communication between employees is a crucial factor in ensuring the flow of information, and substantially reducing an individual's task and role ambiguity by encouraging relational energy [43]. This inevitable transfer of relational energy as employees perform intertwined tasks stimulates social interactions in the form of social support and/or performance feedback, decreasing equivocal task boundaries. Such an effect is once again prompted by ICT presenteeism, which allows employees to effectively interact with colleagues, as its connective feature enables individuals to work with others regardless of time and space.

Although we postulated that both task characteristics interact with ICT presenteeism to further reduce role ambiguity, only task interdependence did so. This may be due to the nature of the task environment as perceived by individuals. Communication technologies may be considered more important in interdependent tasks than in autonomous tasks because interdependent tasks require a greater degree of interaction and communication between employees. When employees work on interdependent tasks, ICT usage substantially assists them in working with each other due to its defiance of time and space, allowing them to attend to their relational selves and adjust relationships and communication demands related to work. As workplace tasks are dynamic, changes made to task activities along the work process may be coordinated more effectively through the use of ICTs.

However, ICT presenteeism did not amplify the negative relationship between task autonomy and role ambiguity. This might stem from the feature of task autonomy, in that it provides employees with the physical and cognitive resources to plan and schedule their work under their own discretion [6]. When equipped with access to such resources, even structural resources delivered in a top-down fashion, individuals take control of their actions and monitor them meticulously, as the behaviors deriving from autonomous planning contribute to their degree of felt responsibility. In this case, individuals may not need additional features in the supporting environment to reduce ambiguity on their roles since they already have sufficient psychological and social resources to clarify their tasks and roles. Thus, by revealing which task characteristic is more strongly affected by ICT presenteeism and is more helpful in decreasing role ambiguity and increasing work engagement, our study provides an in-depth understanding of the boundary conditions and mediating processes affecting work engagement.

In addition, understanding the critical role task environment plays in inducing work engagement is important. Since organizations prefer workers who are immersed in their work, it would be interesting to investigate the structural interdependent factors that may affect the functioning of individuals and/or teams, since individuals increasingly work in team units. Courtright and colleagues (2015) [44] provided an integrative framework and meta-analysis for structural interdependence in teams that involves structural task interdependent factors such as input/resource and process/means and structural outcome interdependent variables including goal interdependence and reward/feedback interdependence affecting team functioning in terms of tasks and relations. Especially notable is that collective efficacy, reflecting the shared desire among members to effectively accomplish various tasks [45] and cohesion, which relates to interpersonal bonds between 
members according to the level of commitment to each other, are induced through the aforementioned interdependence factors [44]. Since work engagement itself involves affective, cognitive, and behavioral dimensions, differential structural factors with disparate characteristics may be important influences on employee engagement.

Finally, role ambiguity was found to be a partial mediator between task interdependence and work engagement. Moreover, both task interdependence and autonomy had a significant negative relationship with role ambiguity. These findings are in line with the JD-R literature's conclusion that key task characteristics reduce hindrance job demands by expanding the resources necessary for task execution. In addition, the significant association between task interdependence and work engagement validates the SDT view that meeting the need for relatedness is beneficial to optimal functioning in workplaces. Although we observed no direct link between task autonomy and work engagement, we found that task autonomy is presumed to indirectly affect work engagement by reducing role ambiguity. Perceiving task autonomy cannot guarantee work engagement, but if employees understand their roles better by utilizing autonomy in performing tasks, they ultimately experience engagement in their work place. Thus, although task autonomy does not of itself contribute to work engagement, it may be associated with enhanced work engagement by resolving role ambiguity. In sum, by elucidating the mechanisms by which different task characteristics promote work engagement, our study provides additional insights for the work engagement literature.

\section{Limitations and Directions for Future Research}

Despite its theoretical and practical implications, our study is not without limitations. First, although our study disclosed two task characteristics that may fulfill individuals' fundamental needs such as competence, autonomy, and relatedness, these are just two of the many characteristics identified in the job design literature. Other job/task characteristics stated in the Job Characteristics Model $[6,36]$ could be taken into consideration to formulate a comprehensive research model that considers job/task characteristics, role stressors, and ICT-based accessibility, as well as the environment as a critical boundary condition of the former two variables. Moreover, though we adopted SDT as our theoretical foundation, key variables identified in SDT (i.e., the need for competence, need for autonomy, need for relatedness) were neither measured nor included in our analyses. Future studies could test SDT in work contexts by examining the relationship between different task characteristics, different SDT needs, and work engagement.

Second, our research design was cross-sectional and used data collected from various organizations at a single point in time. This limits the causal conclusions concerning our study's variables; our findings must thus be interpreted with caution. Although we found that task interdependence affected work engagement by decreasing role ambiguity, it is also plausible that heightened work engagement reduces role ambiguity. Therefore, we urge researchers to conduct additional studies using a more rigorous research design such as experiments intended to better establish causality among task characteristics, role ambiguity, and work engagement. Future research could also benefit from using a longitudinal research design to explore the dynamic process leading to work engagement.

Acknowledgments: This work was supported by the Ministry of Education of the Republic of Korea and the National Research Foundation of Korea (NRF-2015S1A5A2A03048360).

Author Contributions: Sang-Hoon Lee and Yuhyung Shin developed the research model and the questionnaires; Sang-Hoon Lee and Seung Ik Baek analyzed the data and wrote the paper.

Conflicts of Interest: The authors declare no conflict of interest. 


\section{References}

1. Kim, W.; Khan, G.F.; Wood, J.; Mahmood, M.T. Employee engagement for sustainable organizations: Keyword analysis using social network analysis and burst detection approach. Sustainability 2016, 8, 631. [CrossRef]

2. Schaufeli, W.B.; Bakker, A.B. The conceptualization and measurement of work engagement: A review. In Work Engagement: A Handbook of Essential Theory and Research; Bakker, A.B., Leiter, M.P., Eds.; Psychology Press: New York, NY, USA, 2010.

3. Brass, D.J. Structural relationships, job characteristics, and worker satisfaction and performance. Adm. Sci. Q. 1981, 26, 331-348. [CrossRef]

4. Van der Vegt, G.S.; Emans, B.J.M.; Van de Vliert, E. Affective responses to intragroup interdependence and job complexity. J. Manag. 2000, 26, 633-655. [CrossRef]

5. Van der Vegt, G.S.; Van de Vliert, E.; Oosterhof, A. Informational dissimilarity and organizational citizenship behavior: The role of intrateam interdependence and team identification. Acad. Manag. J. 2003, 46, 715-727. [CrossRef]

6. Hackman, J.R.; Oldham, G.R. Development of job diagnostic survey. J. Appl. Psychol. 1975, 60, $159-170$. [CrossRef]

7. Ayyagari, R.; Grover, B.; Purvis, R. Technostress: Technological antecedents and implications. MIS Q. 2011, 35, 831-858.

8. Ragu-Nathan, T.S.; Tarafdar, M.; Ragu-Nathan, B.S.; Tu, Q. The consequences of technostress for end users in organizations: Conceptual development and empirical validation. Inf. Syst. Res. 2008, 19, 417-433. [CrossRef]

9. Tarafdar, M.; Tu, Q.; Ragu-Nathan, B.S.; Ragu-Nathan, T.S. The impact of technostress on role stress and productivity. J. Manag. Inf. Syst. 2007, 24, 301-328. [CrossRef]

10. Bakker, A.B.; Schaufeli, W.B.; Leiter, M.P.; Taris, T.W. Engagement at work: An emerging concept. Work Stress 2008, 22, 185-294. [CrossRef]

11. Deci, E.L.; Ryan, R.M. The "what" and "why" of goal pursuits: Human needs and the self-determination of behavior. Psychol. Inq. 2000, 11, 227-268. [CrossRef]

12. Ryan, R.M.; Deci, E.L. Self-determination theory and the facilitation of intrinsic motivation, social development, and well-being. Am. Psychol. 2000, 55, 68-78. [CrossRef] [PubMed]

13. Deci, E.L.; Ryan, R.M. Intrinsic Motivation and Self-Determination in Human Behavior; Plenum: New York, NY, USA, 1985.

14. Macey, W.H.; Schneider, B. The meaning of employee engagement. Ind. Organ. Psychol. 2008, 1, 3-30. [CrossRef]

15. Van den Broeck, A.; Ferris, D.L.; Chang, C.H.; Rosen, C.C. A Review of Self-Determination Theory's Basic Psychological Needs at Work. J. Manag. 2016, 42, 1195-1229. [CrossRef]

16. Cole, M.S.; Bruch, H.; Vogel, B. Energy at work: A measurement validation and linkage to unit effectiveness. J. Organ. Behav. 2012, 33, 445-467. [CrossRef]

17. Bakker, A.B.; Demerouti, E. Job Demands-Resources Theory. In Wellbeing: A Complete Reference Guide, Work and Wellbeing; Chen, P.Y., Cooper, C.L., Eds.; John Wiley \& Sons: West Sussex, UK, 2014; Volume 3. [CrossRef]

18. Bakker, A.B.; Demerouti, E. The job demands-resources model: State of the art. J. Manag. Psychol. 2007, 22, 209-328. [CrossRef]

19. Bakker, A.B.; Hakanen, J.J.; Demerouti, E.; Xanthopoulou, D. Job resources boost work engagement, particularly when job demands are high. J. Educ. Psychol. 2007, 99, 274-284. [CrossRef]

20. Bakker, A.B.; Van Veldhoven, M.; Xanthopoulou, D. Beyond the demand-control model: Thriving on high job demands and resources. J. Pers. Psychol. 2010, 9, 3-16. [CrossRef]

21. Halbesleben, J.R.B. A meta-analysis of work engagement: Relationships with burnout, demands, resources, and consequences. In Work Engagement: A Handbook of Essential Theory and Research; Bakker, A.B., Leiter, M.P., Eds.; Psychology Press: New York, NY, USA, 2010; pp. 102-117.

22. Schaufeli, W.B.; Bakker, A.B.; Van Rhene, W. How changes in job demands and resources predict burnout, work engagement, and sickness absenteeism. J. Organ. Behav. 2009, 30, 893-917. [CrossRef]

23. Rizzo, J.R.; House, R.J.; Lirtzman, S.I. Role conflict and ambiguity in complex organizations. Adm. Sci. Q. 1970, 15, 150-163. [CrossRef] 
24. Salancik, G.R.; Pfeffer, J. A social information processing approach to job attitudes and task design. Adm. Sci. Q. 1978, 23, 224-253. [CrossRef] [PubMed]

25. Viswesvaran, C.; Sanchez, J.I.; Fisher, J. The role of social support in the process of work stress: A meta-analysis. J. Vocat. Behav. 1999, 54, 314-334. [CrossRef]

26. Mukherjee, A.; Malhotra, N. Does role clarity explain employee-perceived service quality? A study of antecedents and consequences in call centres. Int. J. Ser. Ind. Manag. 2006, 17, 444-473. [CrossRef]

27. Miao, C.F.; Evans, K.R. The interactive effects of sales control systems on salesperson performance-A job demands-resources perspective. J. Acad. Mark. Sci. 2013, 41, 73-90. [CrossRef]

28. Gilboa, S.; Shirom, A.; Fried, Y.; Cooper, C.L. A meta-analysis of work demand stressors and job performance: examining main and moderating effects. Pers. Psychol. 2008, 61, 227-271. [CrossRef]

29. LePine, J.A.; Podsakoff, N.P.; Lepine, M.A. A meta-analytic test of the challenge stressor-hindrance stressor framework: An explanation for inconsistent relationships among stressors and performance. Acad. Manag. J. 2005, 48, 764-775. [CrossRef]

30. Schaufeli, W.B.; Taris, T.W. The conceptualization and measurement of burnout: Common ground and worlds apart. Work Stress 2005, 19, 256-262. [CrossRef]

31. Bandura, A. Self-efficacy: Toward a unifying theory of behavioral change. Psychol. Rev. 1977, 84, $191-215$. [CrossRef] [PubMed]

32. Bandura, A. The self-system in reciprocal determinism. Am. Psychol. 1978, 33, 344-358. [CrossRef]

33. Daft, R.L.; Lengel, R.H. Organizational informational requirements, media richness and structural design. Manag. Sci. 1986, 32, 554-571. [CrossRef]

34. Daft, R.L.; Lengel, R.H.; Trevino, L.K. Message equivocality, media selection, and manager performance: Implications for information systems. MIS Q. 1987, 11, 355-366. [CrossRef]

35. Fujimoto, Y.; Ferdous, A.S.; Sekiguchi, T.; Sugianto, L. The effect of mobile technology usage on work engagement and emotional exhaustion in Japan. J. Bus. Res. 2016, 69, 3315-3323. [CrossRef]

36. Campion, M.A.; Medsker, G.J.; Higgs, A.C. Relations between work group characteristics and effectiveness: Implications for designing effective work groups. Pers. Psychol. 1993, 46, 823-850. [CrossRef]

37. Brislin, R.W. The Wording and Translation of Research Instruments. In Field Methods in Cross-Cultural Research; Lonner, W.L., Berry, J.W., Eds.; Sage: Newbury Park, CA, USA, 1986.

38. Hackman, J.R.; Oldham, G.R. Work Redesign; Addison-Wesley: Reading, MA, USA, 1980.

39. Schaufeli, W.B.; Bakker, A.B.; Salanova, M. The measurement of work engagement with a short questionnaire: A cross-national study. Educ. Psychol. Meas. 2006, 66, 701-716. [CrossRef]

40. Podsakoff, P.M.; MacKenzie, S.B.; Lee, J.; Podsakoff, N.P. Common method biases in behavioral research: A critical review of the literature and recommended remedies. J. Appl. Psychol. 2003, 88, 879-903. [CrossRef] [PubMed]

41. Burke, M.J.; Brief, A.P.; George, J.M. The role of negative affectivity in understanding relations between self-reports of stressors and strains: A comment on the applied psychology literature. J. Appl. Psychol. 1993, 78, 402-412. [CrossRef] [PubMed]

42. Baron, R.M.; Kenny, D.A. The moderate-mediator variable distinction in social psychological research: Conceptual, strategic, and statistical considerations. J. Personal. Soc. Psychol. 1986, 51, 1173-1182. [CrossRef]

43. Owens, B.P.; Baker, W.E.; Sumpter, D.M.; Cameron, K.S. Relational energy at work: Implications for job engagement and job performance. J. Appl. Psychol. 2016, 101, 35-49. [CrossRef] [PubMed]

44. Courtright, S.H.; Thurgood, G.R.; Stewart, G.L.; Pierotti, A.J. Structural interdependence in teams: An integrative framework and meta-analysis. J. Appl. Psychol. 2015, 100, 1825-1846. [CrossRef] [PubMed]

45. Bandura, A. Self-Efficacy: The Exercise of Control; Freeman: New York, NY, USA, 1997.

(C) 2017 by the authors. Licensee MDPI, Basel, Switzerland. This article is an open access article distributed under the terms and conditions of the Creative Commons Attribution (CC BY) license (http:/ / creativecommons.org/licenses/by/4.0/). 